\title{
An Amœba from the Intestine of an Ascidian at Plymouth.
}

\author{
By \\ D. L. Mackinnon, D.Sc., \\ and \\ H. N. Ray, $\mathrm{Ph} . \mathrm{D}$., \\ From the Zoology Department, King's College, London.
}

With 3 Figures in the Text.

While working at Plymouth in December, 1928, and in August, 1930, we noticed amœbæ in the intestine of Phallusia mamillata (Cuvier) which had been dredged in the Sound. The ten animals examined were all infected. The only previous record we can find of an amœba in such a situation is a short account given by Huxley (1920) of a small form occurring in large quantities in the stomach of Clavellina lepadiformis at Naples. The amœbæ we have seen are not like those from Clavellina and they seem to merit some description.

The wall of the intestine was carefully slit open and a drop of the brownish fluid contents was drawn off with a fine pipette and examined on a slide. The movements of the parasite, though sluggish, are sufficiently obvious to enable one to distinguish it easily from epithelial débris and other material in the gut.

This is a small amœba, though larger than the one in Clavellina. When active, it is always longer than broad, and, fully outstretched, measures from $15-30 \mu \times 10-15 \mu$. Its most characteristic feature in the living condition is the tendency to form a wide "sole " of clear, glassy ectoplasm, above which rests the main mass of the body, much as the visceral hump of a snail is supported on the muscular foot.

This ectoplasmic sole protrudes as a broad pseudopodium in front, and posteriorly it tapers to a narrow, finger-like lobe. When we used an oilimmersion lens and racked slightly up and down, so that the amœba wobbled under pressure from the cover-glass, we found that it usually remained firmly tethered to the glass or to the intestinal débris by the posterior lobe, while the rest of the body swung clear and might even roll half over. There is very little movement of translation: the amœba contents itself with emitting the broad anterior pseudopodium, then withdrawing this and forming another slightly to the right or left of the first. 
In the otherwise hyaline protoplasm of the pseudopodium there often lies a group of small refringent granules. The hump-like mass above the sole is granular and opaque, and its surface tends to be thrown into wrinkles. As a pseudopodium is forming, a number of little knob-like

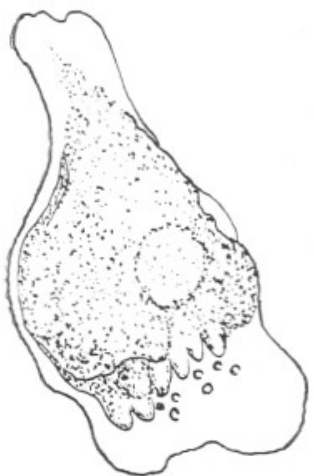

A.

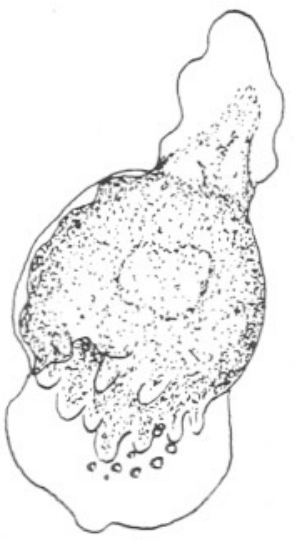

B.

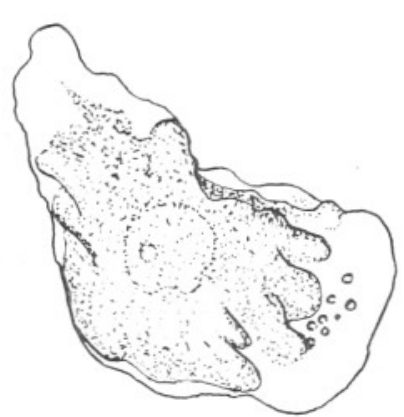

C.

Fig. 1.-A, B, and C. Three sketches of living Entamoba phallusia, all showing the characteristic "sole" of glassy ectoplasm, with the endoplasmic hump above it. $\times 2000$.

projections of endoplasm appear for a short time between it and the main mass. There is no contractile vacuole. We have not seen the amœba engulf anything, and the granules in the protoplasm do not seem to be food material ; it is probable that the organism absorbs its food in a fluid

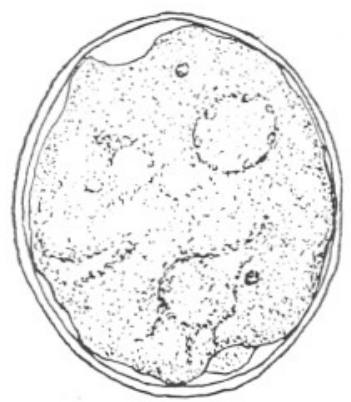

FIG. 2.-Living cyst of Entamœba phallusia. $\quad \times 2000$.

state, and the strings and irregular groups of refringent granules that occur in the protoplasm may be excretory matter. The nucleus measures about $4 \cdot 5 \mu-5 \mu$ in diameter. It is very difficult to detect when the amœba is healthy; but the organism survives removal from its host for only a short time, and as it becomes moribund, the nucleus shows up as a clearer 
space, roughly circular in outline but readily deformed by the endoplasmic streaming. Refringent chromatin beads can sometimes be seen just within the membrane, but only very rarely is the karyosome visible in the living nucleus.

We have found a few cysts (Fig. 2). These measure about $21 \mu \times 19 \mu$. There is a smooth, double-contoured envelope, about $\cdot 8 \mu$ thick, and within this the amœba can be seen lying, its surface somewhat folded, and with slight spaces, especially towards one pole, between it and the wall. We have never seen more than one nucleus in a cyst.

When films of the intestinal contents of Phallusia were fixed in Schaudinn's fluid or Brasil's modification of Bouin-Duboscq, the amœba usually contracted very much and became almost circular in outline; only occasionally did we find one with pseudopodium well outstretched.

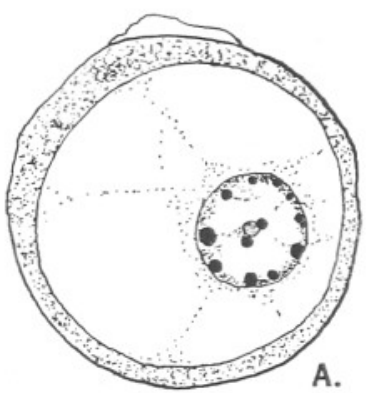

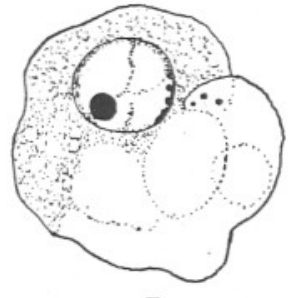

B.

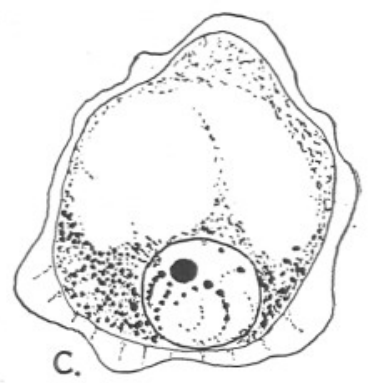

Fig. 3.-A, B, and C. Three amœbæ fixed with Brasil's modification of Bouin-Duboscq and stained with iron hæmatoxylin. The specimens show the retraction of the ectoplasm and the tendency for a large vacuole to appear in the endoplasm. $\times 2500$.

Stained with Heidenhain's iron-hæmatoxylin, such amœbæ show a narrow rim of light-grey homogeneous ectoplasm : the hump invariably appears to contain one relatively enormous vacuole, towards one side of which most of the dark-staining, granular endoplasm is squeezed. Strands of this darker substance criss-cross the vacuolar region, and in one patch, situated almost anywhere near the periphery, lies the nucleus. The refringent inclusions observed in the living organism stain uniformly black and there is no sign of vacuoles around them. The nucleus presents very different appearances according to the amount of its distortion from the spherical and to the angle from which it is viewed. The membrane is delicate; the chromatin is in peripheral beads, and often these are connected together in two or three strings just within the membrane; the karyosome, now very conspicuous but varying greatly in the degree to which it retains the stain, is almost always excentric. We did not find any dividing forms, nor did we see any cysts in the stained preparations.

We have decided to call this amœba Entamœba phallusice n. sp. The 
fact that it has no contractile vacuole does not necessarily suggest that it is a true endoparasite, since the absence of such a structure is the rule in marine amœbæ. But since it seems to feed by imbibing liquid through its whole surface, this indicates that it is rather specially adapted to an endoparasitic life, and it is much more intolerant than are most " facultative " amœbæ of changes in the medium in which it crawls. Its nucleus is not like that of most entamœbæ, if we take the nuclei of Entamoba histolyica and $E$. coli as typical ; it most closely resembles that of the Entamœba described by Dobell (1914) from the hind-gut of Lacerta muralis - a form which he considered quite distinct from Amoba lacertœ Hartmann. This amœba from Lacerta, however, was packed with foodballs. Until we know something concerning the behaviour of the nucleus in mitosis it would be rash to speculate further concerning the relationships of $E$. phallusia with other parasitic amœbæ.

\section{REFERENCES.}

Dobell, C. (1914.) Cytological studies on three species of Amœba. Arch. f. Protistenk, Bd. 34, p. 139.

Huxuey, J. S. (1920.) Notes on an amœba-like parasite from Clavellina. Quart. Journ. Microsc. Sci., Vol. 64, p. 413. 